\title{
Aus dem Vorwort zur dritten Auflage.
}

... Die neue Spektraltafel, die in der zweiten Auflage gebracht worden ist, wurde nach den in dem niederländischen Lehrbuch der Physik von Bosscha-Sissingr enthaltenen Tafeln zusammengestellt, doch hat sich ergeben, daB diese aus H. Erdmann übernommen sind.

Groningen (Niederlande), November 1904.

A. F. Holleman.

\section{Aus dem Vorwort zur achten Auflage.}

... Bei dieser neuen Auflage empting ich wieder von studentischer Seite die Mitteilung einiger Druckfehler, die leider sich trotz aller Sorgfalt in der siebenten Auflage vorfanden. Ich benutze diese Gelegenheit, den betreffenden Herren auch hier dafür meinen aufrichtigsten Dank auszudrücken und mir den Nachweis solcher Fehler auch für die Zukunft zu erbitten.

Amsterdam, Ende Mai 1910.

A. F. Holleman.

\section{Vorwort zur dreizehnten Auflage.}

Außer kleineren Ergänzungen, wie die technische Darstellungsweisen von Wasserstoff, und von Ammoniak nach SERPEK, die neueren Untersuchungen über die Allotropie des Phosphors, die Bestimmung der wahren Stärke der Kohlensäure, und manchen anderen, wurden neu aufgenommen: 
1. Die Untersuchungen Stocks über die Silane (Siliciumwasserstoffrerbindungen); 2. die Untersuchungen von FAJANs, Richards u. a. über isotope Elemente; 3. die Hypothese von RuTHERForD über die Struktur der Atome und in Zusammenhang damit, vaN DEN BROEKs Ordnungszahl der Elemente.

Durch die Ausdehnung, die der Abschnitt der radioaktiven Elemente allmählich erhalten hat, war ab \$ 267 eine neue Paragraphierung unumgänglich.

Amsterdam, Ende Juni 1916.

\section{A. F. Holleman.}

\section{Chronologie.}

1. Auflage: Mai 1900; 2. Auflage: April 1903; 3. Auflage: November 1904; 4. Auflage: April 1906; 5. Auflage: Juli 1907; 6. Auflage: September 1908;

7. Auflage: Oktober 1909; 8. Auflage: Juni 1910; 9. Auflage: Mai 1911; 10. erhöhte Auflage: April 1912; 11. Auflage: April 1913; 12. erhöhte Auflage: Mai 1914; 13. Auflage: Juli 1916. 